\title{
Rapid Estimate of Inadequate Health Literacy (REIHL): development and validation of a practitioner-friendly health literacy screening tool for older adults
}

\author{
Angela YM Leung *, Esther YT Yu, James KH Luk, PH Chau, Diane Levin-Zamir, Isaac SH Leung, \\ KT Cheung, Iris Chi
}

\section{A B S T R A C T}

Introduction: This study aimed to develop and validate a brief practitioner-friendly health literacy screening tool, called Rapid Estimate of Inadequate Health Literacy (REIHL), that estimates patients' health literacy inadequacy in demanding clinical settings.

Methods: This is a methodological study of 304 community-dwelling older adults recruited from one community health centre and five district elderly community centres. Logistic regression models were used to identify the coefficients of the REIHL score's significant factors. Receiver operating characteristic (ROC) curve analysis was then used to assess the REIHL's sensitivity and specificity. Path analysis was employed to examine the REIHL's criterion validity with the Chinese Health Literacy Scale for Chronic Care and concurrent validity with self-rated health scale and the Geriatric Depression Scale-15.

Results: The REIHL has scores ranging from 0 to 23. It had $76.9 \%$ agreement with the Chinese Health Literacy Scale for Chronic Care. The area under the ROC curve for predicting health literacy inadequacy was $0.82(95 \%$ confidence interval=0.78-0.87, $\mathrm{P}<0.001)$. The ROC curve of the REIHL showed that scores $\geq 11$ had a sensitivity of $77.8 \%$ and specificity of $75.6 \%$ for predicting health literacy inadequacy. The path analysis model showed excellent fit (Chi squared

This article was published on 25 Sep 2020 at www.hkmj.org. $[2,304] 0.16, \mathrm{P}=0.92$, comparative fit index 1.00 , root mean square error of approximation <0.001, 90\% confidence interval $=0.00-0.04)$, indicating that the
REIHL has good criterion and concurrent validity.

Conclusion: The newly developed REIHL is a practical tool for estimating older adults' inadequate health literacy in clinical care settings.

\section{Hong Kong Med J 2020;26:404-12}

https://doi.org/10.12809/hkmj208395

${ }^{1}$ AYM Leung *, PhD, FHKAN (Gerontology)

2 EYT Yu, FHKCFP, FHKAM (Family Medicine)

${ }^{3}$ JKH Luk, FHKCP, FHKAM (Medicine)

${ }^{4} \mathrm{PH}$ Chau, PhD

${ }^{5,6}$ D Levin-Zamir, PhD

${ }^{1}$ ISH Leung, MPhil

${ }^{7}$ KT Cheung, MPhil

${ }^{8}$ I Chi, DSW

Centre for Gerontological Nursing, School of Nursing, The Hong Kong Polytechnic University, Hong Kong

2 Department of Family Medicine and Primary Care, Li Ka Shing Faculty of Medicine, The University of Hong Kong, Hong Kong

${ }^{3}$ Department of Medicine, Fung Yiu King Hospital, Hong Kong

${ }^{4}$ School of Nursing, Li Ka Shing Faculty of Medicine, The University of Hong Kong, Hong Kong

${ }^{5}$ Department of Health Education and Promotion, Clalit Health Services, Israel

School of Public Health, University of Haifa, Israel

Centre on Research and Advocacy, Hong Kong Society for Rehabilitation, Hong Kong

${ }^{8}$ USC Suzanne Dworak-Peck School of Social Work, University of Southern California, Los Angeles, United States

* Corresponding author: angela.ym.leung@polyu.edu.hk

New knowledge added by this study

This paper contributes to the field of health literacy and primary care by:

- providing a practitioner-friendly tool for estimating individuals' health literacy inadequacy without interrupting clinical workflow; and

- screening high-risk people in China for comprehensive health literacy assessment with the Chinese Health Literacy Scale for Chronic Care.

Implications for clinical practice or policy

- Using this rapid estimation may allow doctors/nurses to avoid asking patients to complete a questionnaire, which may interrupt the clinical workflow or take up substantial time during medical consultations.

- The Rapid Estimate of Inadequate Health Literacy could also encourage practitioners to spend more time with those who have inadequate health literacy in health education and counselling. 


\section{Introduction}

Health literacy is the ability to obtain, read, understand, and use healthcare information to make appropriate health decisions and follow treatment instructions. Inadequate health literacy (IHL) is a public health concern that is associated with poor health outcomes and frequent use of health services. ${ }^{1}$ Identifying groups at risk for IHL is therefore crucial. Screening tools such as the Rapid Evaluation of Adult Literacy in Medicine-Revised (REALM-R), ${ }^{2}$ Rapid Evaluation of Adult Literacy in Medicine-Short form, ${ }^{3}$ Wide Range Achievement Test (WRAT-4), ${ }^{4}$ Newest Vital Sign (NVS), ${ }^{5}$ and Single-Item Literacy Screener ${ }^{6}$ have been developed for assessment of patients' health literacy. Nonetheless, each of those tools has limitations, hindering the extensive use of rapid health literacy screening in clinical settings.

The REALM-R, Rapid Evaluation of Adult Literacy in Medicine-Short form, and WRAT-4 focus only on word recognition, ${ }^{7}$ representing a narrow concept of health literacy and failing to address two other crucial dimensions: 'interpretation of health information' and 'health decision making.7,8 The REALM-R and WRAT-4 health literacy assessments require 2 to 3 and 3 to 5 minutes, respectively, to administer. Thus, using the REALM-R or WRAT-4 demands special arrangements in clinical settings: patients may be required to complete them prior to consultation, and they may interrupt the usual clinical workflow. An alternative is for the doctor to conduct the assessment, but the typical out-patient clinical consultation period is about 7 minutes for each patient, and adequate health literacy assessment would occupy multiple minutes of this period.

The NVS is another recommended tool for quick health literacy screening that compensates for the shortcomings of previous tools by addressing the need to understand and interpret health information from a designated nutritional label. After reading the label, the client answers six questions about it. The assessment of these capacities by the NVS is both a strength and a shortcoming, as it requires more time to complete. ${ }^{9}$ Notably, older adults take 11.7 minutes (range, 6-28 minutes) to complete the NVS, so its practicality for quick assessment of elderly patients' health literacy is limited. ${ }^{10}$

Another rapid health literacy assessment tool is the Short-Form Test of Functional Health Literacy in Adults, a 36-item tool that assesses clients' comprehension and numeracy abilities. ${ }^{11}$ It is recommended to allot 7 minutes to complete the assessment, and clients should stop when that time is up. However, time-limited assessments can be challenging for older adults because of their delayed cognitive processing or age-related slowness. These effects are typical but not pathological with age, rendering the Short-Form Test of Functional Health Literacy in Adults inappropriate for this population. ${ }^{12}$
健康素飨不足的風險評估：對從業者友好的 較年長人士健康素養篩查工具的開發及驗證

梁綺雯、余懿德、陸嘉熙、周珮馨、Diane Levin-Zamir、 梁思謙、張冠庭、齊銥

引言：本研究旨在開發和驗證一種對從業者友好的精簡健康素養篩查 工具, 稱為 $「$ 快速預測健康素養不足工具」（REIHL）。這工具可用 作評估患者在繁忙的臨床環境中的健康素養不足情況。

方法: 從一間社區健康中心和五間地區老年社區中心招募304例社區 較年長人士進行方法研究。使用邏輯迴歸模型來確定REIHL得分的重 要因素的係數, 然後使用接受者操作特性（ROC）曲線分析來評估 REIHL的敏感性和特異性。運用通徑分析檢驗REIHL的標準效度和中 文慢性疾病健康認知量表, 以及自評健康量表和老年抑鬱量表的同時 效度。

結果：REIHL得分介乎 0 到 23 。它與中文慢性疾病健康認知量表的一 致性達 $76.9 \%$ 。預測健康素養不足的ROC曲線下面積為0.82（95\%置 信區間=0.78-0.87，P<0.001）。REIHL的ROC曲線顯示得分 11 或以 上可預測健康素養不足, 敏感性為 $77.8 \%$, 特異性為 $75.6 \%$ 。通徑分析 模型顯示出極佳的擬合度（卡方 $[2,304] 0.16 、 \mathrm{P}=0.92$ 、比較擬合指 數 1.00 、估計誤差均方根 $<0.001 、 90 \%$ 置信區間=0.00-0.04），表明 REIHL具有良好的標準效度和同時效度。

結論：新開發的REIHL是一種實用工具, 可用作評估較年長人士在臨 床護理環境中的健康素養不足情況。

Further, most of its contents were based on the US healthcare system, making its generalisability to other countries questionable.

The Single-Item Health Literacy Screening is the simplest health literacy assessment, containing only one item. Its key limitation is possible selfreport bias, as it assesses clients' perceived ability to read and understand health information from written material, which may not reflect their actual abilities. ${ }^{6}$

Given the shortcomings of existing rapid health literacy screening tools and the need to assess patients' health literacy in clinical settings, there is a need to develop a rapid tool for non-Englishspeaking older adults that can be used in different healthcare systems and is based on available patient data. The project team has developed several health literacy tools for Chinese populations, including the Chinese Health Literacy Scale for Diabetes, ${ }^{13}$ Chinese Health Literacy Scale for Chronic Care (CHLCC), ${ }^{14}$ and Chinese Health Literacy Scale for DiabetesMultiple Choice version. ${ }^{15}$ Although these tools can be used in Chinese-speaking populations, they require several minutes for clients to complete, which may not be ideal for rapid screening in busy clinics. Therefore, in this study, we aimed to develop and validate a brief practitioner-friendly health literacy screening tool, the Rapid Estimate of Inadequate Health Literacy (REIHL), which employs a multivariable prediction model to determine patients' risk for IHL in a demanding clinical setting. 


\section{Methods}

\section{Study design and participants}

This is a cross-sectional, methodological study that was conducted from August 2010 to January 2011. The Transparent Reporting of a Multivariable Prediction Model for Individual Prognosis or Diagnosis guidelines were also followed. ${ }^{16}$

Older adults from one community health centre and five district elderly community centres in Hong Kong were recruited. The inclusion criteria were: (1) age $\geq 50$ years; (2) cognitively capable (Short Portable Mental Status Questionnaire Chinese version score $\geq 7$ ); and (3) able to communicate in Cantonese. The sample size calculation was derived from a receiver operating characteristic (ROC) power calculation using the 'power.roc.test' function under the 'pRCO' library in $\mathrm{R}$ version 3.6. Assuming that the newly developed tool's area under the curve 0.60 , type 1 error 0.05 , power 0.8 , and attrition $20 \%$, at least 298 subjects should be recruited. ${ }^{17}$

Recruitment strategies included posters at community centres, monthly meetings, and in-person contact. All participants were interviewed to assess their eligibility to participate. Ethical approval was obtained from the Institutional Review Board of The University of Hong Kong/Hospital Authority Hong Kong West Cluster (Ref UW 09033).

\section{Procedure for developing the Risk Estimate of Inadequate Health Literacy}

The newly developed REIHL screening tool was devised using model estimation. Unlike other scale development, we did not create the items for the REIHL but collected socio-demographic data (age, gender, education level, types of chronic illness) and conducted the CHLCC on the subjects. Scores on the CHLCC were used to determine which subjects had IHL. People with CHLCC scores of $<36$ were considered as having IHL. We then created a dummy variable representing IHL (1: IHL; 0: adequate health literacy). Socio-demographic factors (eg, age, education level, types and number of chronic illnesses) associated with IHL were identified, and these became the items of the REIHL. Chronic illnesses refer to conditions that last 1 year or more and lead to limitations in activities of daily living and/or require ongoing medical attention. ${ }^{18}$

\section{Measurement}

People with IHL were more likely to have more depressive symptoms ${ }^{19,20}$ and poor self-rated health (SRH). ${ }^{21,22}$ We therefore checked the criterion validity and concurrent validity of REIHL with the following validated scales.

The CHLCC was used to check the criterion validity of REIHL. The CHLCC is a 24-item tool for measuring health literacy in Chinese populations with four subscales (remembering, understanding, applying, and analysing). It has good internal (Cronbach's alpha, 0.91) and test-retest (intraclass correlation coefficient, $0.77 ; \mathrm{P}<0.01$ ) reliability. ${ }^{14}$

The Geriatric Depression Scale-15 (GDS-15) and the SRH scale were used to check the REIHL's concurrent validity. The GDS-15 is used to assess older adults' depressive symptoms, ${ }^{23}$ and it has been translated into Chinese and validated in Hong Kong with good psychometric properties (Cronbach's alpha, 0.82; item-total correlation, 0.23-0.66)..$^{24,25}$ Its total score ranges from 0 to 15 , with higher values representing increased depression levels. The SRH is a validated single-item scale for assessing general health status. ${ }^{26}$ It is a subjective assessment of general health, asking 'In the last 3 months, how would you describe your health status?' Five options are given: 'very good,' 'good,' 'fair,' 'poor', or 'very poor', coded as integers from 1 (very good) to 5 (very poor).

\section{Statistical analyses}

There were a few items of missing data, which comprised about $2 \%$ of all data. Missing values were filled in using multiple imputation in SPSS (Windows version 25.0; IBM Corp, Armonk [NY], US). Chi squared tests were used to assess the bivariate relationships between demographic variables and IHL. Logistic regression analyses were used to further assess the multivariate relationships among the factors that were significantly associated with IHL. Model adequacy was evaluated by Nagelkerke's $R^{2}{ }^{27}$ To obtain an optimistic assessment of the model's prediction performance and avoid overfitting, 10-fold cross-validation was used, and error mean square (EMS) was reported. To select the best model, we chose the model with the smallest EMS and lowest Bayesian information criterion (BIC) values. We derived the point scores for REIHL with reference to the Framingham Study Risk Score. ${ }^{16}$ The score for each item of the REIHL is calculated by dividing its coefficient by the smallest coefficient and then rounding up to the next highest integer. The total REIHL score is the sum of the scores of all items in the REIHL.

To test the reliability of the REIHL, we used ROC curve analysis ${ }^{28}$ to assess its sensitivity and specificity. We choose the optimum sensitivity and specificity based on maximisation of Youden's index. ${ }^{29}$ We assessed the corresponding sensitivity and specificity of each potential cut-off point. The chosen cut-off point was the one with the largest Youden's index (ie, sensitivity + specificity -1 ). We also assessed the criterion validity and concurrent validity of REIHL. Criterion validity refers to the stated criterion, that is, the correspondence between the results of this newly developed scale and those of a validated health literacy scale. Concurrent 
validity is the extent to which a test relates to another previously validated metric. Here, we tested the REIHL's criterion validity with the CHLCC and the REIHL's concurrent validity with two health outcomes (depression and SRH). Path analysis ${ }^{30}$ was also used to examine the criterion and concurrent validity of REIHL with a validated health literacy scale (CHLCC) and two health outcomes (depressive symptoms and SRH) using MPlus version 7. ${ }^{31} \mathrm{We}$ assessed three fit indices to determine the goodness of fit of the model: a model with non-significant Chi squared value $(P>0.05)$, comparative fit index $\geq 0.95$, and root mean square error of approximation $\leq 0.10$ was considered to be a well-fitting model. ${ }^{32,33} \mathrm{We}$ also inspected the direction and significance of the standardised estimate coefficients to determine the effects of one variable on another.

\section{Results}

A total of 304 subjects were included in the analysis, of whom 220 (72.4\%) were female. In all, 185 (60.9\%) subjects were shown to have IHL when assessed by the health literacy scale (CHLCC score <36). Age, gender, education level, and number of chronic illnesses were significantly associated with CHLCC (Table 1).

Because gender was significantly correlated with education, we selected education level as the representative variable used in the regression models (Table 2). Model 1 employed a regression model that incorporated age and education, and the results were: Nagelkerke's R ${ }^{2}$ 0.39, EMS 0.15, and BIC 347. To form Model 2, we added five chronic illnesses (ie, diabetes, hypertension, stroke, heart disease, and osteoporosis) into the regression; Nagelkerke's $\mathrm{R}^{2}$ increased to 0.43 , EMS to 0.16, and BIC to 359. In Model 3, the selected chronic illnesses were replaced by the number of chronic illnesses, and Nagelkerke's $\mathrm{R}^{2}$ became 0.40, EMS 0.15, and BIC 346. Because Model 3 had the lowest BIC and EMS values, and its Nagelkerke's $R^{2}$ was comparable to those of the other two models, we considered Model 3 as the best and final model.

The coefficients of age, education level, and number of chronic illnesses were identified in Model 3. The smallest coefficient was 0.34 , and that value was used as the denominator to calculate the score for each item. Age was categorised and scored as $0,4,4$, or 7 ; education level was scored as $0,2,5$, or 11; and chronic illnesses were scored from 0 to 5 depending on their number (Table 3). Therefore, the total REIHL score ranged from 0 to 23 . The REIHL had $76.9 \%$ agreement with the CHLCC, the validated, reliable health literacy scale. The area under the ROC curve for predicting IHL was 0.82 (95\% confidence interval=0.78-0.87, $\mathrm{P}<0.001$; Fig 1). The curve for the REIHL showed that scoring $\geq 11$ had a sensitivity of $77.8 \%$ and specificity of $75.6 \%$ for predicting IHL. This criterion identified $60.9 \%$ of the participants as having IHL.

All of the REIHL items had unique scores except for two items under 'Age' that had the same score (ie, 4) after rounding up. The actual score for those aged 65 to 74 years was $3.71(=1.27 / 0.34)$, whereas that for those aged 75 to 84 years was $4.44(=1.55 / 0.34)$. Because the difference between the actual scores (3.71 and 4.44) was almost 1, we considered the possibility of adjusting the score of the item 'aged 75 to 84 years' to 5 . The sensitivity and specificity of the REIHL were $72.4 \%$ and $79.8 \%$, respectively, when adjusted accordingly. These results were not significantly different from those before adjustment. The agreement between REIHL and CHLCC in the adjusted model was $75.3 \%$, which was lower than that before adjustment. The area under the ROC curve of the adjusted REIHL was 0.83 (ie, very close to the corresponding value of the unadjusted version). In view of the insignificant improvement in psychometric properties, we propose to not adjust the scoring of the item 'aged 75 to 84 years', leaving it as 4 .

TABLE I. Comparison of demographics of subjects with adequate and inadequate health literacy $(n=304)^{*}$

\begin{tabular}{|c|c|c|c|}
\hline Variable & $\begin{array}{l}\text { Adequate health } \\
\text { literacy (CHLCC } \\
\quad \geq 36)[n=119]\end{array}$ & $\begin{array}{c}\text { Inadequate } \\
\text { health literacy } \\
\text { (CHLCC <36) } \\
{[n=185]}\end{array}$ & P value \\
\hline \multicolumn{4}{|l|}{ Gender } \\
\hline Male & $41(34.5 \%)$ & $43(23.2 \%)$ & $<0.001$ \\
\hline Female & $78(65.5 \%)$ & $142(76.8 \%)$ & \\
\hline \multicolumn{4}{|l|}{ Age (years) } \\
\hline$<65$ & 32 (26.9\%) & $11(5.9 \%)$ & $<0.001$ \\
\hline $65-74$ & $41(34.5 \%)$ & $52(28.1 \%)$ & \\
\hline $75-84$ & $42(35.3 \%)$ & $99(53.5 \%)$ & \\
\hline$\geq 85$ & $4(3.4 \%)$ & $23(12.4 \%)$ & \\
\hline \multicolumn{4}{|l|}{ Education level } \\
\hline No formal education & $11(9.2 \%)$ & $99(53.5 \%)$ & $<0.001$ \\
\hline Primary education & $66(55.5 \%)$ & $73(39.5 \%)$ & \\
\hline Junior secondary education & $24(20.2 \%)$ & $10(5.4 \%)$ & \\
\hline $\begin{array}{l}\text { Senior secondary } \\
\text { education or above }\end{array}$ & $18(15.1 \%)$ & $3(1.6 \%)$ & \\
\hline \multicolumn{4}{|l|}{ No. of chronic diseases } \\
\hline 0 & $18(15.1 \%)$ & $15(8.1 \%)$ & $<0.01$ \\
\hline 1 & $55(46.2 \%)$ & $71(38.4 \%)$ & \\
\hline 2 & $33(27.7 \%)$ & $69(37.3 \%)$ & \\
\hline 3 & $13(10.9 \%)$ & $27(14.6 \%)$ & \\
\hline 4 & 0 & $3(1.6 \%)$ & \\
\hline$\geq 5$ & 0 & 0 & \\
\hline
\end{tabular}

Abbreviation: CHLCC = Chinese Health Literacy Scale for Chronic Care

* Data are shown as No. (\%), unless otherwise specified 
TABLE 2. Regression of factors and significance of associations with inadequate health literacy $(n=304)$

\begin{tabular}{|c|c|c|c|c|c|c|}
\hline & \multicolumn{2}{|c|}{ Model 1} & \multicolumn{2}{|c|}{ Model 2} & \multicolumn{2}{|c|}{ Model 3} \\
\hline & Coefficient & $P$ value & Coefficient & $P$ value & Coefficient & $P$ value \\
\hline \multicolumn{7}{|l|}{ Parameter estimation } \\
\hline Intercept & -2.77 & $<0.001$ & -3.54 & $<0.001$ & -3.25 & $<0.001$ \\
\hline \multicolumn{7}{|l|}{ Age (years) } \\
\hline$<65$ & Ref & & Ref & & Ref & \\
\hline $65-74$ & 1.28 & $<0.01$ & 1.37 & $<0.01$ & 1.23 & $<0.01$ \\
\hline $75-84$ & 1.56 & $<0.001$ & 1.58 & 0.001 & 1.52 & 0.001 \\
\hline$\geq 85$ & 2.40 & 0.001 & 2.35 & 0.001 & 2.23 & 0.002 \\
\hline \multicolumn{7}{|l|}{ Education } \\
\hline No formal education & Ref & & Ref & & Ref & \\
\hline Primary education & 0.59 & 0.43 & 0.69 & 0.38 & 0.61 & 0.42 \\
\hline Junior secondary education & 1.57 & 0.02 & 1.70 & 0.02 & 1.59 & 0.02 \\
\hline Senior secondary education or above & 3.58 & $<0.001$ & 3.82 & $<0.001$ & 3.61 & $<0.001$ \\
\hline \multicolumn{7}{|l|}{ Chronic illnesses } \\
\hline Osteoporosis & & & -0.41 & 0.40 & & \\
\hline Hypertension & & & 0.47 & 0.19 & & \\
\hline Stroke & & & 1.37 & 0.01 & & \\
\hline Diabetes & & & 0.52 & 0.10 & & \\
\hline Heart disease & & & -0.28 & 0.47 & & \\
\hline No. of chronic diseases & & & & & 0.34 & $<0.05$ \\
\hline \multicolumn{7}{|l|}{ Fit statistics } \\
\hline Cox $R^{2}$ & 0.29 & & 0.32 & & 0.30 & \\
\hline Nagelkerke's $\mathrm{R}^{2}$ & 0.39 & & 0.43 & & 0.40 & \\
\hline Error mean square from 10 -fold cross-validation & 0.15 & & 0.16 & & 0.15 & \\
\hline Bayesian information criterion & 347 & & 359 & & 346 & \\
\hline
\end{tabular}

TABLE 3. Scoring system of the Rapid Estimate of Inadequate Health Literacy (REIHL)*

\begin{tabular}{lcl}
\hline Part & Score & Conditions \\
\hline Part 1: Age & 0 & Age $<65$ years \\
& 4 & Age 65-74 years \\
& 4 & Age 75-84 years \\
& 7 & Age $>84$ years \\
Part 2: Education level & 0 & Senior secondary education or above \\
& 2 & Junior secondary education \\
& 5 & Primary education \\
Part 3: No. of chronic & 11 & No formal education \\
illnesses $\dagger$ & 0 & Has none of these illnesses \\
& 1 & Has one of these illnesses \\
& 2 & Has two of these illnesses \\
& 3 & Has three of these illnesses \\
& 4 & Has four of these illnesses \\
\hline
\end{tabular}

* The total REIHL score is the sum of all three parts. A REIHL score of $\geq 11$ is considered to show inadequate health literacy. The REIHL score ranges from 0 to 23; the higher the score, the greater the inadequacy

† Chronic illnesses refer to osteoporosis, hypertension, stroke, diabetes, or heart disease
The path analysis model showed excellent fit (Chi squared [2, 304] $0.16, \mathrm{P}=0.92$, comparative fit index 1.00, root mean square error of approximation $<0.001, \quad 90 \%$ confidence interval=0.00-0.04), indicating the criterion validity and concurrent validity of the REIHL (Fig 2). The path between the REIHL and CHLCC $(\beta=-32.69, \mathrm{P}<0.001)$ was statistically significant, implying that the REIHL was significantly negatively associated with the CHLCC. This shows the criterion validity of REIHL with a validated health literacy instrument. A negative association between the two scales is reasonable and expected because the REIHL measures inadequacy, unlike the CHLCC, which measures adequacy. The path between the REIHL and the GDS-15 ( $\beta=0.13$, $\mathrm{P}<0.01)$ was also statistically significant, but the path between the REIHL and SRH was not. This implies that there was a significant relationship between IHL and depressive symptoms. The path between the GDS-15 and SRH $(\beta=1.02, P<0.001)$ was statistically significant, indicating a strong relationship between depression and poor SRH. 


\section{Discussion}

The newly developed REIHL is a reliable screening tool for estimating IHL among older adults in clinical settings. Although REIHL is an estimation tool, it had very good agreement with a validated health literacy measure (CHLCC). This implies that if clinicians have limited time to assess patients' health literacy, they could estimate it using the REIHL rather than actually measuring patients' health literacy levels.

The strengths of the REIHL are its reliability and simplicity. We used several methods to test the tool's reliability. For instance, ROC analysis found that the area under the curve was more than $80 \%$, and the sensitivity and specificity of the REIHL

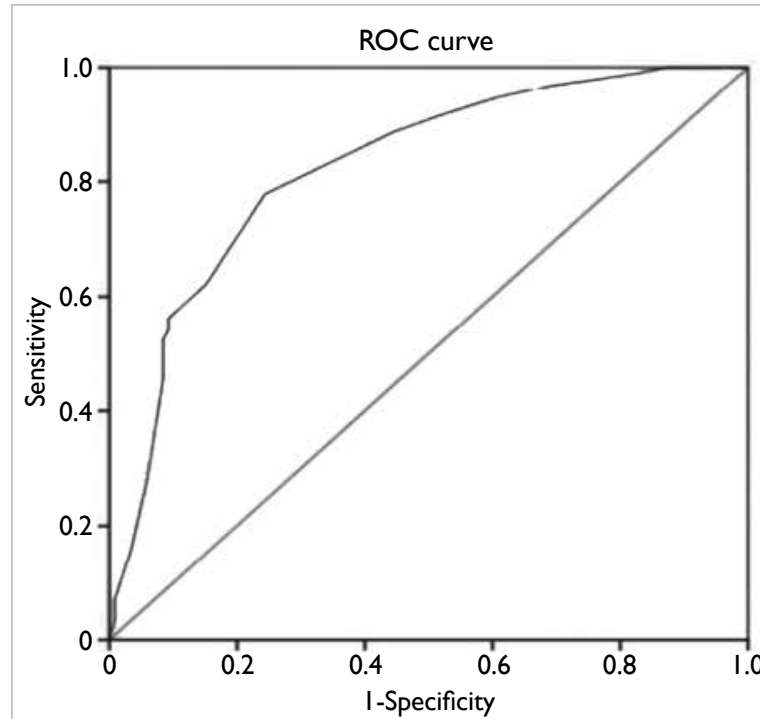

FIG I. Receiver operating characteristic (ROC) curve of the final model with a cut-off point of 11 reached an acceptable level, indicative of an accurate assessment tool. The relationships between REIHL and CHLCC were well illustrated in the path analysis, indicating that REIHL has reasonably good criterion validity. Previous literature showed that adults with IHL were more likely to have depressive symptoms ${ }^{19,20}$ and poor SRH. ${ }^{21,22}$ The path analysis showed that REIHL was significantly associated with GDS-15 but not with SRH; however, the GDS-15 was significantly associated with SRH, and the model showed good fit. These findings confirmed the concurrent validity of REIHL, as estimated IHL was significantly associated with depression. This result provides some added value, as IHL was indirectly associated with poor SRH via depression. This means that older adults' poor SRH was caused not directly by IHL, but by the presence of depression.

Three of the REIHL's items (age, education, and number of chronic illnesses) may be risk factors for depression, so testing the tool's association with depression might be a challenge analogous to testing the relationship between risk factors and poor health outcomes. However, we are confident that the inclusion of these items in the REIHL is a good design choice to highlight the heterogeneity of older adults and remind practitioners to be sensitive to the differentiation among clients. People of advanced age and low education are more likely to have poor health outcomes (including depression), but the age and education level at which practitioners should be mindful of IHL remains unclear. The REIHL is a reminder to practitioners to pay proper attention to these important aspects so that they can communicate with patients to self-manage their health issues. Advocating the use of REIHL is not intended to replace the concept of universal

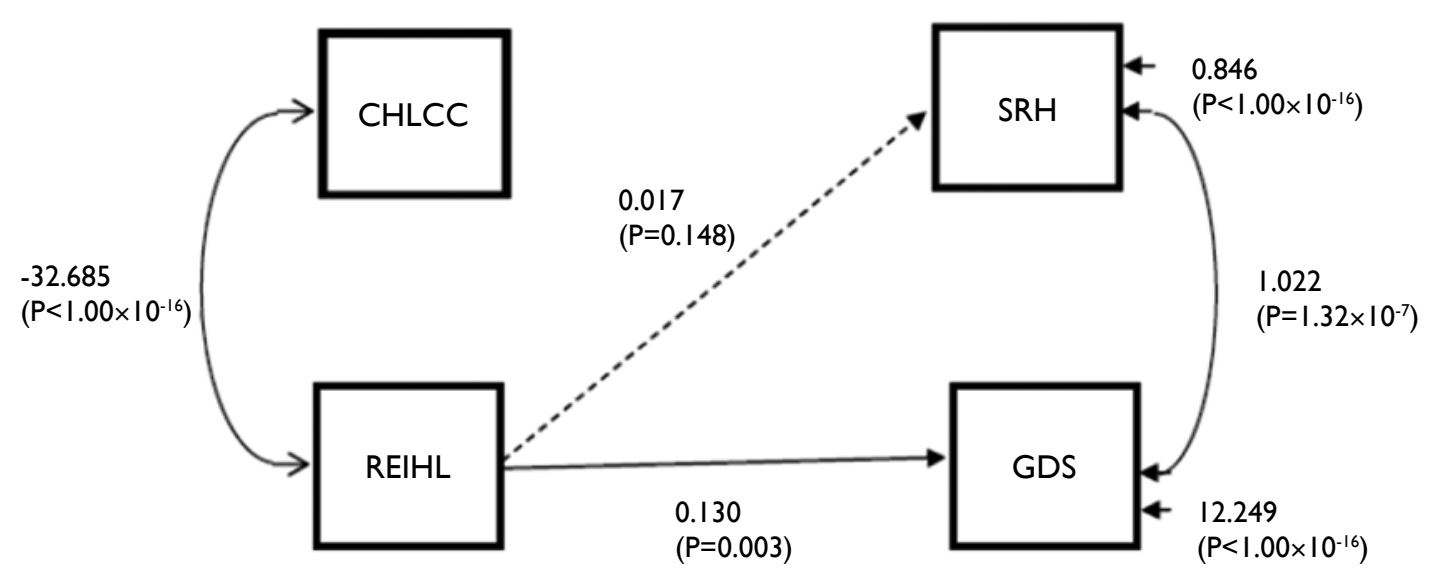

FIG 2. Criterion and concurrent validity of REIHL with a validated health literacy scale and clinical health outcomes Abbreviations: CHLCC = Chinese Health Literacy for Chronic Care (health literacy); GDS = Geriatric Depression Scale-15 (depressive symptoms); REIHL = Rapid Estimate of Inadequate Health Literacy; SRH = self-rated health scale 
precaution in health literacy and its adoption, but it highlights a population that needs special attention regarding health literacy. In clinics where most clients are older adults, practitioners could thereby direct their limited time and resources to those in the greatest need. By contrast, when encountering less-educated clients, some practitioners do not attempt to educate them, assuming they are unable to understand or apply the information. In such situations, the REIHL may encourage practitioners to adopt strategies such as referring clients with IHL to training. In one US study, people with IHL were referred to regular telephone counselling provided by health coaches (trained nurses, health educators, and diabetes educators) for 12 months. ${ }^{34}$ The health coaches delivered health advice/messages in simple sentences over the phone. In a Hong Kong study, multi-component nurse-led group meetings derived from the concept of photovoice were arranged for patients with diabetes, hypertension, and limited health literacy. ${ }^{35}$ In these meetings, participants used photos to express barriers to and facilitators of physical activity and developed plans to improve their health status. ${ }^{35}$ These two examples illustrate how people with IHL have been supported to communicate with healthcare professionals to make their health decisions.

The REIHL can be used easily by clinicians provided that they know the clients' age, education level, and number of chronic illnesses. Its scoring system is simple, with the sum of all items forming the total score. The different levels within each item have unique scores, except for two age categories (65-74 and 75-84 years), to both of which the score 4 was assigned. We investigated the possibility of adding one more point to the latter category's score, but this did not contribute additional sensitivity or specificity; therefore, we decided to keep the status quo.

The REIHL could contribute to the hands-on 1-minute estimation of patients' health literacy levels that is sometimes performed in clinical areas. Such a swift assessment allows practitioners to make decisions in health education, such as avoiding the use of jargon, providing simplified information and illustrations, using the 'teach-back' method, and encouraging patients' questions. These strategies can improve health behaviours among those with IHL. ${ }^{36}$ As IHL is a common phenomenon in clinical settings, the Agency for Healthcare Research and Quality and the Institute for Healthcare Improvement of the US recommend that practitioners use the teach-back method as a strategy of taking universal precautions for health literacy (ie, applying such precautions to all patients). ${ }^{37}$ In the teach-back method, patients are asked to repeat the instructions they receive from doctors and nurses, allowing healthcare professionals to check patients' understanding of the health messages and then re-teach or modify the method of presentation if the patients do not demonstrate comprehension. Throughout the process, it is recommended that doctors and nurses have a caring attitude and use plain language in communication. ${ }^{38}$

Unlike other rapid estimation tools for health literacy, such as the REALM-R, the REIHL does not require clients to read aloud. This enables practitioners to estimate patients' health literacy without embarrassing them, which is particularly suitable to Chinese culture in view of the concept of 'saving face.' Its application is highly recommended in the management of geriatric patients, as such patients are a heterogeneous group in terms of health literacy adequacy. Older patients' literacy problems may not be obvious, as some may conceal their problems out of shame or may not recognise their difficulties with reading. Such individuals may be unable to ask relevant health questions or may misunderstand healthcare providers' recommendations. As older patients tend to have many co-morbidities, they need to navigate the health care system and interpret complex information, which are challenging for people with IHL. Understanding patients' health literacy could allow the implementation of strategies that could potentially improve their health and reduce emergency attendance and hospital admissions. Two strategies have been proven effective to facilitate medication adherence and health literacy. A self-management education programme (two 30- to 40-minute weekly meetings followed by four phone-based educational sessions) tailored to health literacy was shown to increase adherence to antihypertensive medication. ${ }^{39}$ Another strategy is the use of a tailor-made comic book to facilitate medication counselling sessions (two 45-minute face-to-face meetings) administered by trained volunteers. ${ }^{40,41}$ Because people with IHL are more likely to have low confidence in medicine taking, ${ }^{33,42}$ health education of this kind can be beneficial to people with chronic illnesses.

The REIHL is a screening tool for health literacy. Because of its estimated nature and capacity for rapid implementation, it is best used in ambulatory care or out-patient care clinics. The REIHL cannot replace the CHLCC, which assesses health literacy levels accurately and directly. However, the REIHL is good at identifying members of the high-risk population on whom the administration of the CHLCC or other health literacy tests is warranted. The prevalence of IHL in this sample was high (61\%), and this result is comparable to those found in other populations: in the Netherlands, the prevalence of IHL in patients with arterial vascular disease was $76.7 \%,{ }^{43}$ whereas in Brazil, more than half of people with hypertension (54.6\%) had IHL. ${ }^{44}$ As the prevalence of IHL is high across various populations, there should be 
no problems with the generalisation of this health literacy tool. However, to determine whether the REIHL can be applied in other populations or nations, a cross-national study should be carried out in future. ${ }^{45}$

Several limitations of this study should be acknowledged. First, the cross-sectional design did not allow us to investigate the causal relationship between health literacy and health outcomes. Second, because only Chinese subjects were included, the threshold is only valid for Chinese older adults, and whether the results can be generalised to other non-Chinese populations is not known. Future studies should investigate the scale's psychometric properties in other populations. Third, we recruited volunteers from community district elderly centres, so there is some selection bias based on interest and motivation. Further, the tool measures the risk for IHL based on patients' background information; thus, it is not sensitive to changes in an individual's personal health literacy level. Previous studies have shown that cognitive impairment is strongly related to low health literacy. However, we restricted the inclusion criteria to those without impaired cognitive function. ${ }^{46}$ Fourth, the REIHL relies on self-reported items, so under-reporting or over-reporting are possible. Inaccurate reporting may be the result of stigma or the potential for embarrassment associated with low education levels or literacy abilities. Caution should be applied when interpreting REIHL scores. Finally, the present dataset is too small to be split into training and validation datasets. Future studies with larger datasets should be used to validate this scale.

\section{Conclusion}

The REIHL is a practitioner-friendly tool for screening older adults' risk for IHL, which can be applied in clinical settings to identify at-risk groups. This tool is particularly useful in demanding clinical areas where older adults constitute the majority of patients. Future studies should assess how using the REIHL in a community clinical setting encourages healthcare providers to relate better to patients with lower health literacy and improves communication with them.

\section{Author contributions}

Concept or design of study: AYM Leung, PH Chau, I Chi. Acquisition of data: ISH Leung, KT Cheung. Analysis or interpretation of data: All authors. Drafting of the manuscript: ISH Leung, KT Cheung. Critical revision of the manuscript for important intellectual content: AYM Leung, EYT Yu, JKH Luk, D Levin-Zamir, I Chi.

All authors had full access to the data, contributed to the study, approved the final version for publication, and take responsibility for its accuracy and integrity.

\section{Conflicts of interest}

As editors of the journal, JKH Luk and EYT Yu were not involved in the peer review process of the article. Other authors have disclosed no conflicts of interest.

\section{Acknowledgement}

The authors would like to acknowledge the invaluable contribution of the study participants. Special thanks go to the anonymous reviewers for their thoughtful review and guidance.

\section{Declaration}

The findings of this study were presented in part as a poster at the 10th International Symposium on Healthy Aging, Hong Kong. Leung ISH, Leung AYM, Chau PH (2015, March 7-8). Rapid Estimate of Inadequate Health Literacy (REIHL) for community-dwelling Chinese older adults.

\section{Data availability}

The data that support the findings of this study are available on request from the corresponding author. The data are not publicly available because of privacy or ethical restrictions.

\section{Funding/support}

This project was funded by Seed Funding for Basic Research, HKU 2010-11 (Project No: 200911159075) of the University of Hong Kong.

\section{Ethics approval}

Approval was obtained from the Institutional Review Board of The University of Hong Kong/Hospital Authority Hong Kong West Cluster (Ref UW 09-033).

\section{References}

1. Berkman ND, Sheridan SL, Donahue KE, Halpem DJ, Crotty K. Low health literacy and health outcomes: an updated systematic review. Ann Int Med 2011;155:97-107.

2. Davis TC, Long SW, Jackson RH, et al. Rapid estimate of adult literacy in medicine: a shortened screening instrument. Fam Med 1993;25:391-5.

3. Arozullah AM, Yarnold PR, Bennett CL, et al. Development and validation of a short-form, rapid estimate of adult literacy in medicine. Med Care 2007;45:1026-33.

4. Wilkinson GS, Robertson GJ. Wide Range Achievement Test-Fourth Edition (WRAT-4). Lutz, FL: Psychological Assessment Resources; 2006.

5. Weiss BD, Mays MZ, Martz W, et al. Quick assessment of literacy in primary care: the newest vital sign. Ann Fam Med 2005;3:514-22.

6. Morris NS, MacLean CD, Chew LD, Littenberg B. The Single Item Literacy Screener: evaluation of a brief instrument to identify limited reading ability. BMC Fam Pract 2006;7:21.

7. Haun JN, Valerio MA, McCormack LA, Sørensen K, Passche-Orlow MK. Health literacy measurement: an inventory and descriptive summary of 51 instruments. J Health Comm 2014;19 Suppl 2:302-33.

8. Carpenter CR, Kaphingst KA, Goodman MS, Lin MJ, Melson AT, Griffey RT. Feasibility and diagnostic accuracy of brief health literacy and numeracy screening instruments in an urban emergency department. Acad 
Emerg Med 2014;2:137-46.

9. Shah LC, West P, Bremmeyr K, Savoy-Moore RT. Health literacy instrument in family medicine: the "newest vital sign" ease of use and correlates. J Am Board Fam Med 2010;23:195-203.

10. Patel PJ, Joel S, Rovena G, et al. Testing the utility of the newest vital sign (NVS) health literacy assessment tool in older African-American patients. Patient Educ Couns 2011;85:505-7.

11. Baker DW, Williams MV, Parker RM, Gazmararian JA, Nurss J. Development of a brief test to measure functional health literacy. Patient Educ Couns 1999;38:33-42.

12. Robinson S, Moser D, Pelter MM, Besbitt T, Paul SM, Dracup K. Assessing health literacy in heart failure patients. J Card Fail 2011;17:887-92.

13. Leung AY, Lou VW, Cheung MK, Chan SS, Chi I. Development and validation of Chinese health literacy scale for diabetes. J Clin Nurs 2013;22:2090-9.

14. Leung AY, Cheung MK, Lou VW, et al. Development and validation of the Chinese Health Literacy Scale for chronic care. J Health Comm 2013;18 Suppl 1:205-22.

15. Leung AY, Lau HF, Chau PH, Chan EW. Chinese Health Literacy Scale for Diabetes-multiple-choice version (CHLSD-MC): a validation study. J Clin Nurs 2015;24:267982.

16. Sullivan LM, Massaro JM, D’Agostino RB Sr. Presentation of multivariate data for clinical use: The Framingham Study risk score functions. Stat Med 2004;23:1631-60.

17. Li F, He H. Assessing the accuracy of diagnostic tests. Shanghai Arch Psychiatry 2018;30:207-12.

18. Center for Disease Control and Prevention, US Government. About chronic diseases. Available from: https://www.cdc.gov/chronicdisease/about/index.htm. Accessed 17 May 2020.

19. Rhee TG, Lee HY, Kim NK, Han G, Lee J, Kim K. Is health literacy associated with depressive symptoms among Korean adults? Implications for mental health nursing. Perspect Psychiatr Care 2017;53:234-42.

20. Puente-Maestu L, Calle M, Rodríguez-Hermonsa JL, et al. Health literacy and health outcomes in chronic obstructive pulmonary disease. Respir Med 2016;115:78-82.

21. Protheroe J, Whittle R, Bartlam B, Estacio EV, Clark L, Kurth J. Health literacy, associated lifestyle and demographic factors in adult population of an English city: a cross-sectional survey. Health Expect 2017;20:112-9.

22. Liu YB, Liu L, Li YF, Chen YL. Relationship between health literacy, health-related behaviors and health status: a survey of elderly Chinese. Int J Environ Res Public Health 2015;12:9714-25.

23. Sheik JI, Yesavage JA. Geriatric Depression Scale (GDS): recent evidence and development of a shorter version. Clin Gerontol 1986;5:165-73.

24. Lee HC, Chiu HF, Kwok WY, et al. Chinese elderly and the GDS short form: a preliminary study. Clin Gerontol 1993;14:37-42.

25. Boey KW, Chiu HF. Assessing psychological well-being of the old-old: a comparative study of GDS-15 and GHQ-12. Clin Gerontol 1998;19:65-75.

26. Lundberg $\mathrm{O}$, Manderbacka K. Assessing reliability of a measure of self-rated health. Scand J Soc Med 1996;24:21824.

27. Nagelkerke NJ. A note on a general definition of the coefficient of determination. Biometrika 1991;78:691-2.
28. Zweig MH, Campbell G. Receiver-operating characteristic (ROC) plots: a fundamental evaluation tool in clinical medicine. Clin Chem 1993;39:561-77.

29. Ruopp MD, Perkins NJ, Whitcomb BW, Schisterman EF. Youden Index and optimal cut-point estimated from observations affected by a lower limit of detection. Biom J 2008;50:419-30.

30. Garson GD. Path analysis. Asheboro (NC): Statistical Associates Publishers; 2014.

31. Muthén LK, Muthén BO. MPlus (version 6) [computer software]. Los Angeles (CA): Muthén \& Muthén; 2010.

32. Bentler PM. Comparative fit indexes in structural models. Psychol Bull 1990;107:238-46.

33. Raykov T, Marcoulides GA. A First Course in Structural Equation Modeling. 2nd ed. Mahwah (NJ): Erlbaum; 2006.

34. Hadden KB, Arnold CL, Curtis LM, et al. Barriers and solutions to implementing a pragmatic diabetes education trial in rural primary care clinics. Contemp Clin Trials Commun 2020;18:100550.

35. Leung AY, Chau PH, Leung IS, et al. Motivating diabetic and hypertensive patients to engage in regular physical activity: a multi-component intervention derived from the concept of photovoice. Int J Environ Res Public Health 2019;16:1219.

36. Nouri SS, Rudd RE. Health literacy in the "oral exchange": an important element of patient-provider communication. Patient Educ Couns 2015;98:565-71.

37. Yen PH, Leasure AR. Use and effectiveness of the teachback method in patient education and health outcomes. Fed Pract 2019;36:284-9.

38. Warde F, Papadakos J, Papadakos T, Rodin D, Salhia M, Giuliani M. Plain language communication as a priority competency for medical professionals in a globalized world. Can Med Educ J 2018;9:e52-9.

39. Delavar F, Pashaeypoor S, Negarandeh R. The effects of self-management education tailored to health literacy on medication adherence and blood pressure control among elderly people with primary hypertension: a randomized controlled trial. Patient Educ Couns 2020;103:336-42.

40. Leung AY, Leung IS, Liu JW, Ting S, Lo S. Improving health literacy and medication compliance through comic books: a quasi-experimental study in Chinese communitydwelling older adults. Glob Health Promot 2018;25:67-78.

41. Wu SW, Tse DT, Chui JC, et al. Educational comic book versus pamphlet for improvement of health literacy in older patients with type II diabetes mellitus: a randomized controlled trial. Asian J Gerontol Geriatr 2017;12:60-4.

42. Lee YM, Yu HY, You MA, Son YJ. Impact of health literacy on medication adherence in older people with chronic diseases. Collegian 2017;24:11-8.

43. Strijbos RM, Hinnen JW, van den Haak RF, Verhoeven BA, Koning $\mathrm{OH}$. Inadequate health literacy in patients with arterial vascular disease. Eur J Vasc Endovasc Surg 2018;56:239-45.

44. Costa VR, Costa PD, Nakano EY, Apolinário D, Santana AN. Functional health literacy in hypertensive elders at primary health care. Rev Bras Enferm 2019;72 Suppl 2:266-73.

45. Sharma S, Weathers D. Assessing generalizability of scales used in cross-national research. Int J Res Mark 2003;20:287-95.

46. Federman AD, Sano M, Wolf MS, Siu AL, Halm EA. Health literacy and cognitive performance among older adults. J Am Geriatr Soc 2009;57:1475-80. 